\title{
Clinical Non-adherence and Its Associated Factors Among HIV Positive Pediatrics Attending Care in South Gondar Zone Public Health Facilities, Northwest Ethiopia, 2021
}

Chalie Marew Tiruneh ( $\nabla$ marewcha@gmail.com )

Debre Tabor University

Tigabu Desie Emiru

Debre Tabor University

Nigusie Selomon Tibebu

Debre Tabor University

Moges Wubneh Abate

Debre Tabor University

Adane Birhanu Nigat

Debre Tabor University

Berihun Bantie

Debre Tabor University

Amsalu Belete

Debre Tabor University

Belete Gelaw Walle

Wolaita Sodo University

Getasew Legas

Debre Tabor University

Bisrat Dessie Getu

Debre Tabor University

\section{Research Article}

Keywords: clinical adherence, children, antiretroviral, South Gondar, Ethiopia

Posted Date: December 9th, 2021

DOI: https://doi.org/10.21203/rs.3.rs-1124201/v1

License: (c) (1) This work is licensed under a Creative Commons Attribution 4.0 International License. Read Full License 


\section{Abstract}

Background: The most important factor in the success of HIV treatment is clinical adherence. Inadequate clinical adherence is one of the factors that affect the adherence level of highly active antiretroviral treatment and its effect on suppressed viral replication. Even though data from different settings are necessary to tackle it, pieces of evidence are limited especially in the case of clinical adherence level of HIV-infected children. Hence, this study aimed to assess clinical non-adherence level and its associated factors among HIV-positive children on HAART.

Methods: A multicenter cross-sectional study was conducted from July 1 to August 30, 2021, among HIV-infected children on ART in South Gondar Zone. Data were entered into Epi Data Version 4.6 and analysis was done using Statistical Package for Social Science (SPSS) Version 25. Binary logistic regression was implemented to assess the association of factors against the outcome variable and variables with $p$-values $\leq 0.25$ in the bivariable analysis were entered into the multivariable analysis. Finally, variables with $p$-values less than 0.05 were considered statistically significant factors.

Result-out of 384 study participants, 383 were included in this study with a response rate of $99.7 \%$. Nearly half of the study participants 190(49.6\%) were girls. The majority, 291 (76\%) of caretakers were biological mothers, and $203(53 \%)$ did not have treatment supporters. One hundred seventy-nine $(46.7 \%)$ of caretakers did not disclose the status of the child about the illness. The overall prevalence of non-adherence among children on ART was $31.9 \%$ ( 95\% Cl: 27.2-36.6). Rural residency, diagnostic status non-disclosure, no adherence supporter, having no biological caretaker and comorbid illness were significantly associated with clinical non-adherence of HIV positive children.

Conclusion-clinical non-adherence among children among HIV-positive children attending care in south Gondar zone health institutes is unacceptably high. Being rural residency, diagnostic status non-disclosure, no adherence supporter, having non-biological caretaker, and having comorbid illness were significantly associated with clinical non-adherence. Thus, attention shall be given to successful clinical adherence in HIV-positive children who uses the antiretroviral drug.

\section{Background}

At the end of 2019, approximately 36.9 million people were living with HIV globally; of which 1.8 million were, children (age 0-14 years). At the end of 2017, about 21.7 million people living with HIV were accessed antiretroviral treatment(1). In Ethiopia by the end of 2018, an estimated 56,514 children under the age of 15 were living with HIV. Of which, around 2,994 were newly infected with HIV (2)

Antiretroviral therapy (ART) has been shown to delay progression to AIDS, resulting in a greater and more sustained virological and immunologic response and improving survival $(2,3)$. According to recent studies, ART regimens require $70-90 \%$ adherence to be effective. However, sustaining adherence to antiretroviral therapy (ART) over the long term requires accurate and consistent monitoring, and this is a particular challenge for countries in sub-Saharan Africa(3).

Different scholars agree that, if a patient requires the optimum benefits from HAART in terms of suppression of HIV, then that patient needs to comply with a near-perfect adherence to the clinical requirements of the HAART regimen. Inadequate clinical adherence leads to inadequate ART adherence to antiretroviral therapy which further 
leads to treatment failure and the emergence of the resistant virus with eventual exhaustion of treatment options and it leads to treatment failure(4). Clinical adherence is challenged by various social and clinical obstacles, where inadequate suppression of viral replication by ART are resulting due to poor adherence to therapy, low potency of the antiretroviral regimens, viral resistance to antiretroviral medications, and pharmacokinetic interactions(5). The transmissibility of the antiretroviral resistant viruses from person to person further compounds the problem as a clinical and public health challenge(6).

Some caregivers may place too much responsibility for managing medications on older children and adolescents before they are developmentally able to undertake such tasks. Adherence also may be jeopardized by social and health issues within a family (e.g., substance use, poor physical or mental health, unstable housing, poverty, violence, involvement with the criminal justice system, limited social support $(7,8)$.

Although there are different studies on HIV medication adherence (9-13), little is known about the prevalence and factors associated with clinical adherence in HIV-positive children on HAART in the study area. This study aimed to assess the magnitude of clinical non-adherence and its associated factors among HIV-positive children on HAART in South Gondar zone public health institutes. It is expected that the findings generated from this study will contribute to improving the quality of care to HIV-positive pediatrics, and it could be important for planning interventions and effective strategies for maximizing long-term adherence to HAART. The data collected will be used by organizations involved in this area to deal with the problems associated with clinical non-adherence.

\section{Methods}

\section{Study area, design, and period}

A multi-center cross-sectional study was conducted from July 1 to August 30, 2021, among HIV-infected children on ART in South Gondar Zone public health institutes, Northwest Ethiopia, 2021. The study was carried out in six selected health facilities, which are Debre Tabor compressive specialized hospital, Mekane Eyesus primary hospital, Nefas Mewucha primary hospital, Addis Zemen primary hospital, Woreta health center Wogeda hospital. All these and other health facilities in South Gondar Zone provide chronic HIV care and follow-up services for more than 775 HIV-infected children.

\section{Study participants}

All confirmed HIV-positive children (aged $<15$ years) taking ART in South Gondar Zone public health institutes were the target population. All HIV-infected children who had ART follow up at the selected health institutes were the study population. However, children with incomplete baseline medical information, a child who does not have a caretaker or parents to undertake the consent, caretakers diagnosed to have mental problems, or children who have physical malformation and are seriously ill were excluded from the study.

Sample size, and sampling technique

The minimum required sample size was determined using a single population proportion formula. To calculate our sample size, the following statistical assumptions were considered: due to the absence of study on the same problem across the region, $50 \%$ proportion $(p)$ of clinical non-adherence was taken, $5 \%$ margin of error; $5 \%$ nonresponse rate; and $95 \%$ confidence intervals $(\mathrm{Cl})$. 
$\mathrm{n}=\frac{(\mathrm{Za} / 2)^{2} \mathrm{p}(1-\mathrm{p})}{(\mathrm{d})^{2}}=\frac{(1.96)^{2} 0.5(1-0.5)}{(0.05)^{2}}=384$

Where, $n=$ the required sample size, $\mathrm{Za} / 2=$ Standard normal variation for type 1 error, $\mathrm{p}=$ prevalence $(0.5) \& \mathrm{~d}=$ Margin of sampling error tolerated (0.05).

The calculated sample size was 384 . After considering a $5 \%$ non-response rate, the final sample size of our study was 422.

This study was conducted in six randomly selected public health institutes in South Gondar Zone. From the beginning, a sampling frame was prepared using the patient's medical registration number from each hospital's ART registration. Then, the total sample sizes were allocated proportionally for each health institutes. Finally, study participants were taken from each of the six selected health institutes using a computer-generated simple random sampling technique.

Data collection tool and procedure

The data abstraction checklist was developed from the current Ethiopian Federal Ministry of Health ART clinic intake and follow-up forms. Trained health professionals collected data through face-to-face interviews, and document reviews. Training about the objectives of the study, the contents of the tool, and data collection procedures was given for data collectors and supervisors for one day. The pretest was carried out at $5 \%$ of the total sample size at Ebinat hospital. During the data collection time, caregivers who had HIV medication nonadherence children were linked to case managers. The assigned supervisors and principal investigator closely monitored and supervised the whole data collection process.

\section{Operational definitions}

Clinical non-adherence: was defined as HIV-positive children who do not adhere to regularly attending clinical care follow-ups and periodic laboratory monitoring with avoiding practices that interfere with the effect of medication(14).

\section{Data management and statistical analysis}

The consistency and completeness of the collected data were examined during data management and analysis. Data were entered into Epi Data Version 4.6 and analysis was done using Statistical Package for Social Science (SPSS) Version 25. Frequencies and cross-tabulations were used to check for missed values of variables and to describe the study population about relevant variables. Furthermore, percentages, proportions, and summary statistics were used to summarize the study population characteristics. Binary logistic regression analysis was implemented to assess the association of factors against the outcome variable. Variables with $p$-values $\leq 0.25$ in the bivariable analysis were entered into the final model to control the effects of confounders and identify significant factors. Adequacy of the model to fit the outcome variable with the predictors was checked using the Hosmer-Lemeshow test for goodness of fit. In the multivariable analysis, variables with p-values less than 0.05 were considered statistically significant factors. Finally, the strength and the direction of association were assessed using odds ratios with their correspondence $95 \%$ confidence interval. 


\section{Results}

\section{Socio-demographic characteristics of study participants}

Out of 422 study participants, 383 were included in this study with a response rate of $90.7 \%$. Nearly half of the study participants $180(47 \%)$ were girls and $157(41 \%)$ were from rural areas. Children aged less than 60 months were $77(20.1 \%)$, while $147(37.3 \%)$ of the study participants were between 121 and 180 months. The majority 291 $(76 \%)$ of caretakers were biological mothers, and $174(45.4 \%)$ of the caretakers were unable to read and write. Among the children, 203(53\%) did not have treatment support (Table 1).

\section{Clinically related factors}

One hundred twenty -six (32.9\%) of study participants had WHO clinical stage 4 defining illness. Almost one-third of participants $(36 \%)$ had a different comorbid illness. About half $(51.7 \%)$ of study participants had less than sixty months duration on anti-retroviral treatment. One hundred seventy-nine $(46.7 \%)$ of caretakers did not disclose the status of the child about the illness. Eighty-six (22.5\%) of the respondents did not have a continuous drug supply (Table 2).

\section{Prevalence of clinical Non-Adherence}

The overall prevalence of non-adherence among children on ART was $31.9 \%(95 \%$ Cl: 27.2-36.6) (Figure 1).

\section{Factors associated with wasting}

This study examined the relationship between the different participant characteristics and the presence of clinical non-adherence. In the bivariate analysis residency, age, marital status of caretakers, Having a comorbid illness, diagnostic status disclosure, having oral lesion, Having adherence support, caretaker relation with the child, and having diarrhea in the months were found to be eligible variables for adjustment in multivariable analysis. After adjusting for possible confounders in the multivariable analysis residency, diagnostic status disclosure, having adherence support, caretaker relation with the child, and comorbid illness were remained to show statistically significant association with clinical non-adherence of HIV positive children.

The likelihood for the presence of clinical non-adherence was about two times more among the HIV-infected children who live in the rural area (AOR 2.122; $95 \% \mathrm{Cl}=1.299-3.468$ ) compared to those who live in urban. Regarding comorbid illness clinical non-adherence was about one pint seven times ( $A O R=1.741 ; 95 \% \mathrm{Cl}=1.066$ 2.842) more likely to occur in those HIV infected children who have a comorbid illness as compared to those who had no comorbidity. HIV-infected children who were not disclosed their diagnostic status were two times more likely to have clinical non-adherence (AOR=2.011; $95 \% \mathrm{Cl}=1.265-3.195)$ as compared to those HIV positive children who were disclosed their diagnostic status. The likelihood for the present clinical non-adherence was two and half times more among the HIV-infected children who had no adherence support(AOR=2.424; $95 \% \mathrm{Cl}=1.492-$ 3.937) compared to those who had adherence support. Moreover, HIV-positive children who have non-biological mothers were three-point four more likely $(\mathrm{AOR}=3.409 ; 95 \% \mathrm{Cl}=1.979-5.869)$ to have clinical non-adherence than those whose caretakers were biological mothers (Table 3 ).

\section{Discussion}


Clinical non-adherence is commonly encountered in the treatment of children and adolescents with HIV due to various reasons. In the current study, prevalence of clinical non-adherence among the pediatric age group living with HIV/AIDS was 31.9\%( 95\% Cl: 27.2-36.6).

In the present study, children who lived in rural areas were more likely to be clinical non-adherence as compared to those who live in the urban area. This is due to the reason that rural residents have a low probability to involve in social support, they have difficulty accessing health facilities and adherence supporters as compared to urban residents. This can also be justified as rural residents may have a low level of understanding about the disease and treatment which affects adherence level. Moreover, rural residents have transportation problem that needs to be avail in the health setting at the appointment schedule and to conduct requested laboratory tests.

In this study, children who had a comorbid illness were more likely to be clinical non-adherence compared to those who had not a comorbid illness. This is might be due to those who had comorbid illness may get difficulty availing at a schedule, in adhering to the advice given by health care provider and to conducting the ordered laboratory request. This can also be justified as those who have comorbid illness may have an additional schedule in the health institutes for comorbid illness, which makes them have fatigue from multiple schedules.

Finding from this study also revealed that the prevalence of clinical non-adherence was more likely in those HIVpositive children who had no biological caretakers. This might be due to caretakers who are non-biological mothers for HIV-positive children may have low attention to the child and this leads the child to have clinical nonadherence. Children who have no biological mother may be exposed to depression that leads the child to have decreased interest in applying what the health care provider orders for him/her. This also might be due to challenges in the trusty relationship-building process resulting from the negligence of caretakers which further lead the child to have poor clinical adherence.

This study revealed that children who did not know diagnosis status were more likely to be antiretroviral drug non-adherence. This is in line with the study conducted in drug adherence at Gondar(13), Wollo(10), and in a tertiary hospital in Ethiopia(12) of ART. This is due to keeping the child's status secret and not telling his/her problem having a deleterious effect on the discussion of HIV and ART with infected children that increase the chance of the child to cooperate with his/her treatment. This also leads the child not to be enquiring support they need and loss of trust with caretakers which affects their clinical adherence(14).

In this study, children who had no adherence supporter were more likely to be antiretroviral drug non-adherence. This is supported by the scientific evidence of, inconsistent ongoing support and care services, provided by different relatives to children result in poor adherence to follow-up and medication schedules. This is also supported by the scientific evidence of, management of adherence in adolescents is particularly challenging because of the emotional and psychosocial issues that are unique to their developmental stage which needs consistent and continuous support from adherence supporters (14).

\section{Abbreviations}

AIDS: Acquired Immune Deficiency Syndrome; AOR: Adjusted odds ratio; ART: Antiretroviral Therapy; Cl: Confidence Interval; COR: Crud odd ratio; HIV: Human immunodeficiency Virus; Ol: Opportunistic Infection; SPSS: Statistical Package for Social science; WHO: World Health Organization. 


\section{Declarations}

\section{Acknowledgments}

We would like to express our heartfelt gratitude to all selected study site officials whom we have communicated, and indorsed as to conduct this study. Our special thanks also extended to the study participants, data collectors, supervisors, and staff.

\section{Authors' contributions}

All authors have made substantial contributions to this study. The corresponding author conceived and designs the study did the literature search, coordinated the write-up, participated in data analysis, editing, and submission of the article. All co-authors participated in literature search, analysis, and interpretation of data, drafting the article and revising it for important intellectual content, and approve the final version of the manuscript.

\section{Availability of data and materials}

The data sets used and/or analyzed during the current study are available from the Corresponding author upon reasonable request.

\section{Consent for publication}

Not applicable

\section{Ethics approval and consent to participate}

The study was conducted after obtaining ethical clearance from Debre Tabor University, College of health sciences, through an ethical letter with protocol number CHS2519/2021. The study was also done as per the declaration of Helsinki. Informed consent was obtained from the caretaker or parents of study participants after the purpose and procedures of the study were fully informed. To maintain confidentiality participants' names and unique ART numbers were not included in the data collection tool. Moreover, the confidentiality of data was kept at all levels of the study and not used for any other purposes than the stated study objectives.

\section{Competing interests}

The authors declared that they have no competing interests.

\section{References}

1. UNAIDS. Global HIV \& AIDS statistics-2020 fact sheet.. 2020.

2. Ephi. HIV related estimate and projection for Ethiopia Addis Ababa,Available from: https://www.ephi.gov.et/images/pictures/download2009/HIV_estimation_and_projection_for_Ethiopia_2017. 2017.

3. Kharsany $A B$, Karim QA. HIV infection and AIDS in sub-Saharan Africa: current status, challenges and opportunities. The open AIDS journal. 2016;10:34.

4. Williams AB. Adherence to HIV regimens: 10 vital lessons. AJN The American Journal of Nursing. $2001 ; 101(6): 37-43$. 
5. Unaids, HIV/AIDS. JUNPo, Program WBGHA. The global economic crisis and HIV prevention and treatment programmes: vulnerabilities and impact: World Health Organization; 2009.

6. Wainberg MA, Friedland G. Public health implications of antiretroviral therapy and HIV drug resistance. Jama. 1998;279(24):1977-83.

7. Naar-King S, Montepiedra G, Nichols S, Farley J, Garvie PA, Kammerer B, et al. Allocation of family responsibility for illness management in pediatric HIV. Journal of Pediatric Psychology. 2009;34(2):187-94.

8. Cluver LD, Hodes RJ, Toska E, Kidia KK, Orkin FM, Sherr L, et al. 'HIV is like a tsotsi. ARVs are your guns': associations between HIV-disclosure and adherence to antiretroviral treatment among adolescents in South Africa. LWW; 2015.

9. Bezabhe WM, Chalmers L, Bereznicki LR, Peterson GM, Bimirew MA, Kassie DM. Barriers and facilitators of adherence to antiretroviral drug therapy and retention in care among adult HIV-positive patients: a qualitative study from Ethiopia. PloS one. 2014;9(5):e97353.

10. Arage G, Tessema GA, Kassa $\mathrm{H}$. Adherence to antiretroviral therapy and its associated factors among children at South Wollo Zone Hospitals, Northeast Ethiopia: a cross-sectional study. BMC public health. 2014;14(1):1-7.

11. Biadgilign S, Deribew A, Amberbir A, Deribe K. Adherence to highly active antiretroviral therapy and its correlates among HIV infected pediatric patients in Ethiopia. BMC pediatrics. 2008;8(1):1-9.

12. Biressaw S, Abegaz WE, Abebe M, Taye WA, Belay M. Adherence to Antiretroviral Therapy and associated factors among HIV infected children in Ethiopia: unannounced home-based pill count versus caregivers' report. BMC pediatrics. 2013;13(1):1-9.

13. Dachew BA, Tesfahunegn TB, Birhanu AM. Adherence to highly active antiretroviral therapy and associated factors among children at the University of Gondar Hospital and Gondar Poly Clinic, Northwest Ethiopia: a cross-sectional institutional based study. BMC Public health. 2014;14(1):1-6.

14. FMoH E. National consolidated guidelines for comprehensive HIV prevention, care and treatment. Geneva: World Health Organization. 2020.

\section{Tables}

Table 1 Socio demographic characteristics of HIV Positive Pediatrics Attending Care in South Gondar Zone public health facilities 


\begin{tabular}{|c|c|c|c|}
\hline Variable & frequency & \multicolumn{2}{|c|}{ Percentage } \\
\hline \multirow[t]{5}{*}{ Ethnicity } & Amhara & 278 & 72.6 \\
\hline & Tigre & 66 & 17.2 \\
\hline & Oromo & 11 & 2.9 \\
\hline & Other & 28 & 7.3 \\
\hline & Total & 383 & 100.0 \\
\hline \multirow[t]{3}{*}{ Residency } & rural & 116 & 30.3 \\
\hline & urban & 267 & 69.7 \\
\hline & Total & 383 & 100.0 \\
\hline \multirow[t]{3}{*}{ Marital status of caretaker } & currently not married & 282 & 73.6 \\
\hline & currently married & 101 & 26.4 \\
\hline & Total & 383 & 100.0 \\
\hline \multirow[t]{4}{*}{ Monthly income of caretakers in Birr } & $<1500$ & 77 & 20.1 \\
\hline & 1500 to 3000 & 126 & 32.9 \\
\hline & $>3000$ & 180 & 47.0 \\
\hline & Total & 383 & 100.0 \\
\hline \multirow[t]{3}{*}{ Relationship of caretaker with child } & None Biological mother & 92 & 24.0 \\
\hline & Biological mother & 291 & 76.0 \\
\hline & Total & 383 & 100.0 \\
\hline \multirow[t]{4}{*}{ Age of child } & $<60$ month & 77 & 20.1 \\
\hline & 60 to 120 month & 163 & 42.6 \\
\hline & 121 to 180 month & 143 & 37.3 \\
\hline & Total & 383 & 100.0 \\
\hline \multirow[t]{3}{*}{ Sex of child } & Male & 203 & 53 \\
\hline & Female & 180 & 47 \\
\hline & Total & 383 & 100.0 \\
\hline \multirow[t]{4}{*}{ Religion of caretaker } & Protestant & 31 & 8.1 \\
\hline & Orthodox & 327 & 85.4 \\
\hline & Muslim & 25 & 6.5 \\
\hline & Total & 383 & 100.0 \\
\hline Education of care taker & can read and write & 209 & 54.6 \\
\hline
\end{tabular}




\begin{tabular}{|llll|}
\hline & not read and write & 174 & 45.4 \\
\cline { 2 - 3 } Occupation of caretakers & Total & 383 & 100.0 \\
\hline & Government employed & 45 & 11.7 \\
\cline { 2 - 3 } & NGO employed & 41 & 10.7 \\
\hline Merchant & 126 & 32.9 \\
\hline Daily Laborer & 152 & 39.7 \\
\hline Other (specify) & 19 & 5.0 \\
\hline Total & 383 & 100.0 \\
\hline Number of family & $<4$ & 146 & 38.1 \\
\hline$>=4$ & 237 & 61.9 \\
\hline Total & 383 & 100.0 \\
\hline yes & 180 & 47.0 \\
\hline no & 203 & 53.0 \\
\hline Total & 383 & 100.0 \\
\hline
\end{tabular}

Table 2 Clinical related factors of HIV Positive Pediatrics Attending Care in South Gondar Zone public health facilities. 


\begin{tabular}{|c|c|c|c|}
\hline Variable & Category & frequency & Percentage \\
\hline \multirow[t]{5}{*}{ WHO stage } & Stage 1 & 121 & 31.6 \\
\hline & stage 2 & 38 & 9.9 \\
\hline & stage 3 & 98 & 25.6 \\
\hline & stage 4 & 126 & 32.9 \\
\hline & Total & 383 & 100.0 \\
\hline \multirow[t]{3}{*}{ Child having diarrhea in the last one month } & YES & 166 & 43.3 \\
\hline & NO & 217 & 56.7 \\
\hline & Total & 383 & 100.0 \\
\hline \multirow[t]{3}{*}{ Presence of oral lesion in the last one month } & YES & 178 & 46.5 \\
\hline & NO & 205 & 53.5 \\
\hline & Total & 383 & 100.0 \\
\hline \multirow[t]{3}{*}{ Any comorbid illness in the last one month } & YES & 138 & 36.0 \\
\hline & NO & 245 & 64.0 \\
\hline & Total & 383 & 100.0 \\
\hline \multirow[t]{3}{*}{ Have continuous drug supply } & yes & 297 & 77.5 \\
\hline & no & 86 & 22.5 \\
\hline & Total & 383 & 100.0 \\
\hline \multirow[t]{3}{*}{ Child is disclosed for his illness } & YES & 204 & 53.3 \\
\hline & NO & 179 & 46.7 \\
\hline & Total & 383 & 100.0 \\
\hline \multirow[t]{4}{*}{ Duration on ART in month } & $<60$ & 198 & 51.7 \\
\hline & $61-120$ & 80 & 20.9 \\
\hline & $121-180$ & 105 & 27.4 \\
\hline & Total & 383 & 100.0 \\
\hline \multirow[t]{3}{*}{ ART drug adherence } & have adherence & 261 & 68.1 \\
\hline & None adherence & 122 & 31.9 \\
\hline & Total & 383 & 100.0 \\
\hline \multirow[t]{3}{*}{ Reason for none adherence } & Forgetfulness & 46 & 37.7 \\
\hline & Too ill & 30 & 24.6 \\
\hline & fear of stigma & 27 & 22.1 \\
\hline
\end{tabular}




\begin{tabular}{lcc} 
travel problem & 19 & 15.6 \\
\hline Total & 122 & 100.0
\end{tabular}

Table 3 Bivariable and multivariable analysis of HIV positive children attending ART care at public health institutions in South Gondar, Amhara, Ethiopia, 2021 


\begin{tabular}{|c|c|c|c|c|c|c|}
\hline \multirow{2}{*}{$\begin{array}{l}\text { Variable and } \\
\text { Category }\end{array}$} & \multicolumn{2}{|c|}{ Adherence level } & \multicolumn{2}{|c|}{$\begin{array}{l}\text { Bi-variable logistic } \\
\text { regression analysis }\end{array}$} & \multicolumn{2}{|c|}{$\begin{array}{l}\text { Multi-variable logistic } \\
\text { regression analysis }\end{array}$} \\
\hline & $\begin{array}{l}\text { None } \\
\text { adhere N } \\
(\%)\end{array}$ & $\begin{array}{l}\text { Adhere N } \\
(\%)\end{array}$ & $\begin{array}{l}\mathrm{p}- \\
\text { value }\end{array}$ & COR with $95 \% \mathrm{Cl}$ & $\begin{array}{l}\text { AOR with 95\% } \\
\mathrm{Cl}\end{array}$ & $\begin{array}{l}\text { P- } \\
\text { Value }\end{array}$ \\
\hline \multicolumn{7}{|l|}{ Residency } \\
\hline Rural & $50(41 \%)$ & $66(25.3 \%)$ & .002 & $\begin{array}{l}2.052(1.300- \\
3.238)\end{array}$ & $\begin{array}{l}2.122(1.299- \\
3.468)\end{array}$ & $0.003^{*}$ \\
\hline Urban & $195(74.7 \%)$ & $72(59 \%)$ & 1 & & & \\
\hline \multicolumn{7}{|l|}{ Age in month } \\
\hline$<60$ & $30(24.6 \%)$ & $47(18 \%)$ & .121 & $\begin{array}{l}1.588(0.885- \\
2.848)\end{array}$ & $\begin{array}{l}1.734(0.917- \\
3.278)\end{array}$ & 0.090 \\
\hline $60-120$ & $51(41.5 \%)$ & $112(42.9 \%)$ & .618 & $\begin{array}{l}1.133(0.693- \\
1.851)\end{array}$ & & \\
\hline $121-180$ & $41(33.6 \%)$ & 102(39.1\%) & & 1 & & \\
\hline \multicolumn{7}{|l|}{$\begin{array}{l}\text { Marital status of } \\
\text { caretakers }\end{array}$} \\
\hline $\begin{array}{l}\text { Currently not } \\
\text { married }\end{array}$ & $98(80.3 \%)$ & $184(70.5 \%)$ & .043 & $\begin{array}{l}1.709(1.016- \\
2.873)\end{array}$ & $\begin{array}{l}1.402(0.795- \\
2.473)\end{array}$ & 0.243 \\
\hline Currently married & $24(19.7 \%)$ & $77(29.5 \%)$ & & 1 & & \\
\hline \multicolumn{7}{|c|}{ Have comorbid illness } \\
\hline Yes & $49(40.2 \%)$ & $89(34.1 \%)$ & 0.250 & $\begin{array}{l}1.297(833- \\
2.021)\end{array}$ & $\begin{array}{l}1.741(1.066- \\
2.842)\end{array}$ & $\begin{array}{l}0 \\
.027 *\end{array}$ \\
\hline No & $172(65.9 \%)$ & $73(59.8 \%)$ & 1 & & & \\
\hline \multicolumn{7}{|l|}{ Having diarrhea } \\
\hline Yes & $61(51.2 \%)$ & $105(40.2 \%)$ & .073 & $\begin{array}{l}1.486(.964- \\
2.290)\end{array}$ & $\begin{array}{l}1.395(0.863- \\
2.258)\end{array}$ & 0.175 \\
\hline No & $61(48.8 \%)$ & $156(59.8 \%)$ & 1 & & & \\
\hline \multicolumn{7}{|l|}{ Status disclosed } \\
\hline No & $73(50 \%)$ & $106(40.6 \%)$ & .000 & $\begin{array}{l}2.178(1.406- \\
3.377)\end{array}$ & $\begin{array}{l}2.011(1.265- \\
3.195)\end{array}$ & $0.03^{\star}$ \\
\hline Yes & $155(59.4 \%)$ & $49(50 \%)$ & 1 & & & \\
\hline \multicolumn{7}{|l|}{ Oral lesion } \\
\hline Yes & $63(51.6 \%)$ & $115(44.1 \%)$ & .167 & $\begin{array}{l}1.356(.881- \\
2.086)\end{array}$ & $\begin{array}{l}1.159(0.700- \\
1.917)\end{array}$ & 0.566 \\
\hline No & $49(49.4 \%)$ & $146(55.9 \%)$ & 1 & & & \\
\hline \multicolumn{7}{|c|}{ Have adherence support } \\
\hline No & $77(63.1 \%)$ & $126(48.3 \%)$ & .007 & 1.833(1.180- & 2.424(1.492- & $0.000 *$ \\
\hline
\end{tabular}




\begin{tabular}{|lcccccc}
\hline Yes & $135(51.7 \%)$ & $45(36.9 \%)$ & 1 & & & \\
\hline Care takers relation & & & & & & \\
Other than mother & $44(36.1 \%)$ & $48(18.4 \%)$ & .000 & $\begin{array}{l}2.503(1.542- \\
4.063)\end{array}$ & $\begin{array}{c}3.409(1.979- \\
5.869)\end{array}$ & $0.000 *$ \\
\hline Biological mother & $213(81.6 \%)$ & $78(62.9 \%)$ & 1 & & & \\
\hline
\end{tabular}

\section{Reference}

*- significantly associated with outcome variable

\section{Figures}

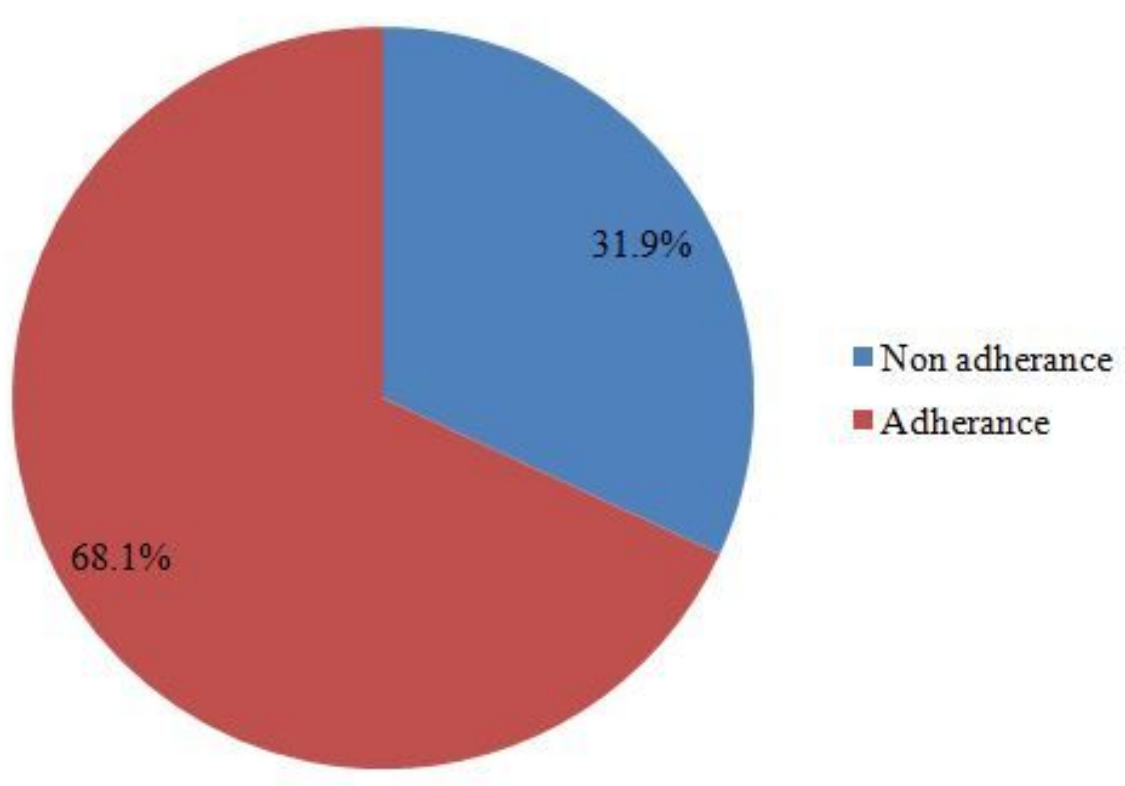

\section{Figure 1}

Prevalence of clinical none adherence among HIV Positive Pediatrics Attending Care in South Gondar Zone public health facilities 